\title{
Caetana e Inácia: duas histórias de mulheres na sociedade escravocrata brasileira"
}

\author{
Elciene Azevedo* \\ Mariana Françozo ***
}

Lançado nos Estados Unidos em 2002, o mais recente livro da historiadora Sandra Lauderdale Graham trata de um tema tão relevante quanto polêmico. Autora de um estudo sobre a relação entre escravas e senhores no Rio de Janeiro na segunda metade do século XIX (Proteção e Obediência, Companhia das Letras, 1992), Sandra Graham analisa, desta feita, duas histórias de mulheres que viveram em fazendas de café na região do Vale do Paraíba entre as décadas de 1830 e 1860 , e que a seu próprio modo questionaram as regras implícitas de um mundo social em que os homens ocupavam os postos de comando.

A primeira mulher que a historiadora nos apresenta é Caetana, escrava de 17 anos, pertencente ao dono da fazenda Rio Claro Luís Mariano de Tolosa, que em 1835 decidiu casá-la com um outro escravo seu. Até aí, nada especial - sabemos muito bem em que medida a vida dos escravos esteve sujeita às vontades, mandos e desmandos de seus senhores. O que é surpreendente nesta história é que Caetana não apenas negou os votos do matrimônio, como também conseguiu que seu senhor a ajudasse na tentativa de anular judicialmente o casamento. A segunda

\footnotetext{
" Resenha do livro: Graham, Sandra Lauderdale. Caetana diz não. Histórias de Mulheres da Sociedade Escravista Brasileira. São Paulo, Cia. das Letras, 2005, 289 pp.

*** Pesquisadora do Centro de História Social da Cultura - Cecult/Unicamp. elciene@terra.com.br

****Doutoranda em Ciências Sociais - IFCH/Unicamp. mariana_f@terra.com.br
} 


\section{Caetana e Inácia}

mulher é Inácia, ou melhor, Dona Inácia Delfina Werneck - que, como senhora branca da classe dominante, tinha direito a título, nome e sobrenome. Esta senhora, aos 86 anos, ditou ao redator de seu testamento o seu último desejo: após sua morte, a família de sua escrava Bernardina deveria receber, como herança, um determinado número de escravos - ato de generosidade, talvez, que certamente garantiria a sobrevivência material de Bernardina e seus filhos após a morte de sua proprietária. Ato incomum, sem sombra de dúvida, não só porque oferecia parte de seus bens justamente àqueles que, até então, faziam parte deste mesmo conjunto de sua propriedade material, mas sobretudo porque, ao libertar Bernardina e seus filhos e garantir-lhes a sobrevivência, Inácia desempenhava o papel masculino de provedora. Caetana e Inácia não eram somente mulheres com vontade própria num mundo governado por homens, mas antes de tudo mulheres que usaram dos meios de que dispunham para fazer sua vontade valer, negociando, nos termos correntes, com os homens aos quais deviam obediência.

Caetana diz não, portanto, é um livro sobre as regras de um mundo social específico - aquele da escravidão na região rural das províncias de São Paulo e Rio de Janeiro no século XIX - e como elas foram vividas por duas mulheres diferentes. Ao invés de aceitar a dominação masculina como um fato dado e reiterar o argumento simplista de que as mulheres, nesta história, não tinham vez, Sandra Graham mostra como é possível, desta vez, entender a história a partir das vidas singulares de mulheres. Num belíssimo trabalho de micro-história, a autora parte da petição de anulamento depositada no tribunal eclesiástico de Salvador para reconstruir os passos e assim a história de Caetana. Do mesmo modo, a partir do testamento de Inácia Werneck, e do de sua irmã, Francisca Lauriana das Chagas, Graham vai atrás de toda a genealogia da família Werneck para em seguida entender o sentido das ações desta filha de família de cafeicultores.

Sandra Graham consegue reconstruir com maestria as histórias de seus personagens e os cenários onde estas se 
desenrolaram. As fontes cartoriais - inventários, testamentos e processos judiciais - amparadas por almanaques, mapas de população, correspondências oficiais e pessoais, permitem que a autora transporte seus leitores para dentro das cercanias das fazendas de Tolosa e Inácia e acompanhem aspectos importantes de seus cotidianos. Mas, além disso, fontes privilegiadas para se observar as tensões e solidariedades geradas nas relações sociais, as fontes judiciais são também exploradas pela autora no que trazem de forma indireta: os sentidos e os significados das ações e escolhas dos sujeitos que nelas aparecem. Graham busca, assim, entender a dinâmica das relações sociais que perpassam esses documentos, olhando tanto para os aspectos miúdos da vida social que daí surgem, quanto para os significados dos inúmeros conflitos que expressam.

Além disso, a tentativa de recuperar e reconstruir a história destas mulheres com máxima precisão leva a um resultado muito frutífero. Em primeiro lugar, é evidente, o leitor ganha maior proximidade com os episódios narrados e pode apreciá-los a partir de um quadro mais completo. Em segundo lugar, justamente por ir a fundo nos detalhes, a autora permite que se localize uma série de questões que por vezes tangenciam sua narrativa, mas que são de central importância para seu argumento, como ela mesma deixa entrever.

No caso da história de Caetana, por exemplo, Graham levanta uma hipótese interessante quanto às motivações de Tolosa para querer casar a moça. Sendo ela uma escrava doméstica, estava em contato íntimo e permanente com os filhos e filhas do senhor. Assim, afirma Graham, Caetana poderia ser tanto uma má influência para suas filhas solteiras, "pelo exemplo de sua inevitável conduta sexual" ao permanecer solteira (p.76), quanto ser alvo dos desejos de seus filhos homens, que poderiam ter sua iniciação sexual com ela (p.77). Desgostoso com as duas possibilidades, Tolosa teria decidido casar Caetana e assim conter ou controlar sua sexualidade. A hipótese é bastante plausível, mas o que interessa aqui é que nestas duas páginas, isto é, neste 
pequeno trecho do livro, Graham tocou num ponto crucial para o entendimento das relações entre senhores e escravos: o da intimidade doméstica e da sexualidade - tema, aliás, do qual a autora tratou em seu primeiro livro, já citado. Como pensar o que significava e que papéis desempenhava uma escrava doméstica numa fazenda em que viviam filhos e filhas solteiras do senhor? Em que medida a sexualidade das escravas entrava em conflito ou compunha a trajetória de aprendizado de papéis sexuais numa sociedade tão marcada por relações violentas?

No mesmo sentido, na história de Inácia tem-se a descrição de um evento que pode chamar atenção para outra série de questões. Graham revela os desígnios de Inácia quanto ao seu sepultamento, indicando em que cemitério deveria ser enterrada, caso morresse em tal ou qual freguesia, e detalhando as esmolas que deveriam ser distribuídas aos duzentos pobres que deveriam acompanhar a procissão até o túmulo (p.127). Com tal descrição, Sandra Graham convida a uma reflexão sociológica à la Norbert Elias sobre o poder simbólico do ritual funerário e as implicações da morte para o mundo dos vivos.

Traduzido para o português com cuidado, mas pecando por algumas frases truncadas, o livro aparece no Brasil em boa hora. $\mathrm{Na}$ esteira de uma série de estudos sobre a história da escravidão que, desde o início da década de 1980, vêm questionando o lugar de vítima passiva geralmente conferido aos escravos nas interpretações sobre o período escravocrata no Brasil, Caetana diz não articula esta perspectiva à questão de gênero - que, por sua vez, também vem ganhando destaque e diferenciação no meio acadêmico brasileiro nas últimas décadas. Aliando a preocupação em revelar as histórias individuais, as ações, estratégias e escolhas dos sujeitos históricos com o olhar atento às relações entre homens e mulheres - ou melhor, às relações que constituem o que se entende por papéis masculinos e papéis femininos - o novo livro de Graham tem como recorte a historia da escravidão a partir do enfoque de gênero. 
Esta escolha acertada da pesquisadora, contudo, conduz a alguns problemas. Como afirmado, trata-se de um estudo em que as relações de gênero têm papel central. Porém, as análises são feitas quase que única e exclusivamente a partir de relações de gênero. Sandra Graham parte do pressuposto de que a história do Brasil é marcada pela dominação masculina, pelo patriarcado. Pode-se concordar com essa afirmação, mas não sem que se pondere o que é este patriarcado e de que maneiras ele opera e se manifesta. Assim, não se pode concordar, no caso da história de Caetana, que tanto seu proprietário, Tolosa, quanto seu tio e padrinho, Alexandre, queriam que ela se casasse motivados por um mesmo sentimento ou temor: se Caetana não o fizesse, estaria infringindo as regras de dominação e o patriarcado estaria, deste modo, ameaçado. Ora, evidentemente não se pode comparar a relação de Tolosa e Caetana com a relação de Alexandre e Caetana - e, tampouco, a ligação entre Tolosa e Alexandre! Em outras palavras, por mais que o poder masculino estivesse sendo questionado, Alexandre insistia no casamento de sua sobrinha menos por medo da ameaça ao patriarcado e mais porque assim obedecia Tolosa, seu proprietário. O tio de Caetana, sendo um dos escravos privilegiados pelo senhor, não poderia ousar tomar o lado da sobrinha em detrimento daquele a quem ele devia obediência. Se o gênero é fundamental para entendermos o início e o desfecho desta história, não o é menos a relação de classe entre um senhor e seus escravos.

A história de Inácia fornece mais um exemplo de como o argumento do patriarcado, sozinho, não explica todas as questões levantadas. Sandra Graham transcreve e comenta, frase por frase, alguns trechos do testamento de Inácia. Em dado momento, compara-o com o de sua irmã, Francisca, e então passa a revelar um fato importante (p.136). Doze anos mais moça que Inácia, Francisca, como a irmã, nunca se casou, porém teve um filho $e$ não apenas o criou como tal como fez questão de garantir, através de seu testamento, que ele seria seu herdeiro legítimo após sua morte. Segundo Graham, o fato de Francisca ter sido mãe solteira 


\section{Caetana e Inácia}

não foi motivo de discórdia entre a família. O filho, Felício, não só foi reconhecido como também se tornou um fazendeiro de sucesso e figura pública importante do município de Vassouras (p.137). Ora, como entender esse fato? Graham não vai adiante nas hipóteses. Porém, para o leitor surge uma questão: se, no caso da história de Caetana, sua sexualidade deveria ser controlada como forma de não ameaçar o patriarcado, como Francisca pôde ter um filho solteira? Sua sexualidade tinha status diferente daquele da de Caetana? Francisca não precisava ser controlada? Falta aqui o dado da posição social de cada uma dessas mulheres. Sendo parte de família rica, Francisca pôde ter seu filho e criá-lo para ser figura de destaque na sociedade. Talvez seja preciso pensar em que medida o status social, o capital material e a pertença à elite particularizavam as relações de gênero.

$\mathrm{Na}$ conclusão de seu livro, a autora afirma que

...a escravidão era uma rede, não apenas e nem mesmo principalmente de relações de trabalho (...), mas antes uma rede de relações sociais entre pessoas de condições legais, recursos, mobilidade, instrução e poder radicalmente distintas... (p.222).

Assim, por que não pensar também as relações de gênero articuladas com os outros tipos de relação que localizavam socialmente os indivíduos? As próprias histórias de Caetana e Inácia indicam que diferenças de classe e de raça, entre outras, davam o tom daquilo que uma mulher poderia ou não fazer naquela sociedade, bem como dos papéis dos homens na mesma.

Graças a uma pesquisa exaustiva, Caetana diz não apresenta os casos estudados num nível de detalhe que recria o contexto em que os personagens viveram com riqueza $e$ complexidade. Não é por acaso que este livro figura em vários programas de disciplinas nos cursos de história de diversas universidades norte-americanas. Neste sentido, a edição brasileira da obra conta com um adendo que a torna especialmente profícua para o uso em sala de aula. Nas suas reflexões finais, 
Graham tece uma bela história da história - uma explicação de como e porquê a micro-história surgiu nos países mediterrâneos, bem como um balanço crítico da bibliografia brasileira com a qual ela dialoga. Assim, tem-se não só um didático mapeamento da literatura sobre o tema, como também uma sincera tomada de posição de Graham sobre suas escolhas teóricas e motivações de pesquisa.

Surpreendente pelas histórias que recupera, envolvente pela narrativa que apresenta, fundamental pelo tema que aborda, este é um livro para todos aqueles interessados na história da escravidão e na história das relações de gênero no Brasil. 